\title{
RADIOCARBON MEASUREMENT PROGRAM AT THE CENTRO NACIONAL DE ACELERADORES (CNA), SPAIN
}

\author{
F Javier Santos Arévalo ${ }^{1}$ Isabel Gómez Martínez • Manuel García León \\ Centro Nacional de Aceleradores, Av. Thomas Alva Edison 7, 41092, Seville, Spain.
}

ABSTRACT. In September 2005, an accelerator mass spectrometry (AMS) system based on a 1MV Tandetron accelerator arrived at the Centro Nacional de Aceleradores (CNA). One of the main research programs for this AMS facility is based on radiocarbon. At the same time as the AMS facility was installed and tested, the ${ }^{14} \mathrm{C}$ sample preparation laboratory was designed and set up. A graphitization line that allows the preparation of 5 samples in parallel was designed and built in October 2006. The first months were mainly dedicated to check and optimize all the sample processing. For such a task, several reference samples have been prepared and measured. Since the beginning of 2007, the laboratory has been fully operational and is currently performing as a service for the scientific community. During 2007, nearly 100 unknown samples were prepared and measured in our AMS system. Most of them were for dating purposes, but also other applications were investigated. The performance of the ${ }^{14} \mathrm{C}$ laboratory and dating service will be shown, with some examples as illustration.

\section{INTRODUCTION}

Radiocarbon dating has proved to be a very valuable technique in many fields of research. Especially in archaeology, it has been widely used and has helped to understand the past in a large context. Spain is a country with a very long and rich history, and many researchers use ${ }^{14} \mathrm{C}$ in their investigations. Unfortunately, only radiometric laboratories existed in Spain, and small samples that needed accelerator mass spectrometry (AMS) had to be sent to foreign AMS facilities, resulting in higher costs and thus reducing the amount of samples that could be measured. One of the main objectives of the new AMS facility at CNA in Spain is to improve the research capabilities of Spanish investigators in the fields were ${ }^{14} \mathrm{C}$ dating may be useful. The complete process of sample preparation, measurement, and data analysis is performed at CNA.

\section{SAMPLE PREPARATION}

One of the major advantages of AMS over radiometric methods for ${ }^{14} \mathrm{C}$ dating is the much smaller amount of sample needed. This allows the use of the technique for very small or valuable samples that should not be damaged significantly.

Sample preparation is performed in a laboratory specifically created for ${ }^{14} \mathrm{C}$. The rest of the isotopes measured at the AMS facility of the CNA (Chamizo et al. 2008) are prepared in a different laboratory. Only conventional milligram-size samples are prepared at CNA, since the sample preparation lab is not prepared for submilligram samples. Graphite is produced from samples following standard methods in 3 main steps: 1) pretreatment, 2) production of $\mathrm{CO}_{2}$, and 3) graphitization to produce a solid sample to measure by AMS. Even though the ion source is capable of measuring gaseous samples, it has not been tested yet.

The pretreatment procedure depends on the type of sample. The usual method is using acid-alkaliacid (Olsson 1986) using $0.5 \mathrm{M} \mathrm{HCl}$ and $0.1 \mathrm{M} \mathrm{NaOH}$. This is used for charcoal, wood, textiles, peat, grains, and similar materials. The intensity of the treatment depends on the quantity and fragility of the sample. For bone samples, we apply the Longin method to extract the collagen (Longin 1971), combined with AAA cleaning (as explained in Arslanov and Svezhentsev [1993] and Piotrowska

${ }^{1}$ Corresponding author. Email: fsantos@us.es.

(C) 2009 by the Arizona Board of Regents on behalf of the University of Arizona

Proceedings of the 5th International ${ }^{14} \mathrm{C}$ and Archaeology Symposium, edited by Irka Hajdas et al.

RADIOCARBON, Vol 51, Nr 2, 2009, p 883-889 
and Goslar [2002]). In the case of carbonate samples, an initial leaching with $\mathrm{HCl}$ is used to decompose and eliminate the outer and most likely contaminated part of the sample.

Organic solvents are used in a Soxhlet-type apparatus to remove contamination produced by conservation chemicals (oil, dye, glue, etc.) that may have been added to the sample. Three different solvents in an elutropic sequence are used: hexane, acetone, and ethanol, for $30 \mathrm{~min}$ each. This is done only on samples subjected to this kind of contamination, before the AAA cleaning.

$\mathrm{CO}_{2}$ is produced either by combustion or by complete leaching with phosphoric acid to decompose carbonates in the case of such samples. In the case of combustion, $\mathrm{CuO}$ is added to provide oxygen and $\mathrm{Ag}$ powder is used to eliminate contaminants. Combustion takes place in a vacuum-sealed quartz tube at $950{ }^{\circ} \mathrm{C}$ for $3 \mathrm{hr}$.

The graphitization line is based on the existing at ETH/PSI radiocarbon laboratory (Hajdas et al. 2004), but all the instrumentation is manually controlled. $\mathrm{CO}_{2}$ is transformed into graphite by the addition of $\mathrm{H}_{2}$ in the presence of Co as a catalyst. The reaction lasts for about $4 \mathrm{hr}$ and is performed at $625^{\circ} \mathrm{C}$. The combusted samples are introduced in the line and the amount of gas is measured. A constant amount of the total is cryogenically transferred to the reactors, corresponding to $\sim 1.7 \mathrm{mg}$ of carbon. The mixture of cobalt and carbon is pressed in the cathodes and kept in a vacuum box until measurement.

\section{PERFORMANCE OF THE AMS SYSTEM}

The CNA AMS facility has been previously described (Klein et al. 2006, 2007; Chamizo et al. 2008). Here, we present some results on the performance for ${ }^{14} \mathrm{C}$ measurements from samples prepared at our lab.

The long-term stability of the measurements can be seen in measurements of the ${ }^{14} \mathrm{C} /{ }^{12} \mathrm{C}$ ratio in different HOxII cathodes, as represented in Figure 1. Values are taken from a real measurement process, lasting several hours from the first to last data of each individual cathode. For each cathode, several runs were measured, alternating cathodes in between. Each run comprised 10 cycles of 20 seconds. The typical extracted ${ }^{12} \mathrm{C}^{-}$current was about $20-25 \mu \mathrm{A}$. The average of the runs for each individual cathode is shown. Internal (statistical) error and standard deviation of the mean (SDOM) for each cathode are also presented (\%), showing very good agreement. The mean value of the averages of the cathodes, $1.40261(0.14 / 0.18)$, also compares well with the mean value of all the runs taken individually, $1.40243(0.14 / 0.14)$.

Also important for precise dating, the ${ }^{13} \mathrm{C} /{ }^{12} \mathrm{C}$ ratio is measured quasi-simultaneously to ${ }^{14} \mathrm{C} /{ }^{12} \mathrm{C}$ ratio. Since the acceptance tests, it was obvious that the ${ }^{13} \mathrm{C} /{ }^{12} \mathrm{C}$ ratio showed a clear correlation with the current, in such a way that higher currents from the source will correspond to higher ${ }^{13} \mathrm{C} /{ }^{12} \mathrm{C}$ ratios (Klein et al. 2007). This effect leads to different results for the samples depending on the current they provide, and thus a correction factor is needed to normalize the values of the samples to the same reference current. This correction factor is applied to every sample individually and it ranges between $3-10 \times 10^{-6}\left(\mu \mathrm{A}{ }^{12} \mathrm{C}\right)$ for samples between $10-40 \mu \mathrm{A}$. Below $10 \mu \mathrm{A}$, the behavior of the beam seems to change drastically and the correction is not valid anymore. Such samples are not considered as viable. In general, samples measured in the same batch do not present such a high range of currents, varying between 20-30 $\mu \mathrm{A}$. This correction is currently under study in order to find the best approach to correct values. Up to now, it is clear that the correction factor does not depend only on the current; it also depends on the sample itself. Probably the geometry of the target pressed material has some effect. Results are shown for the same set of samples in Figure 2. SDOM of the 


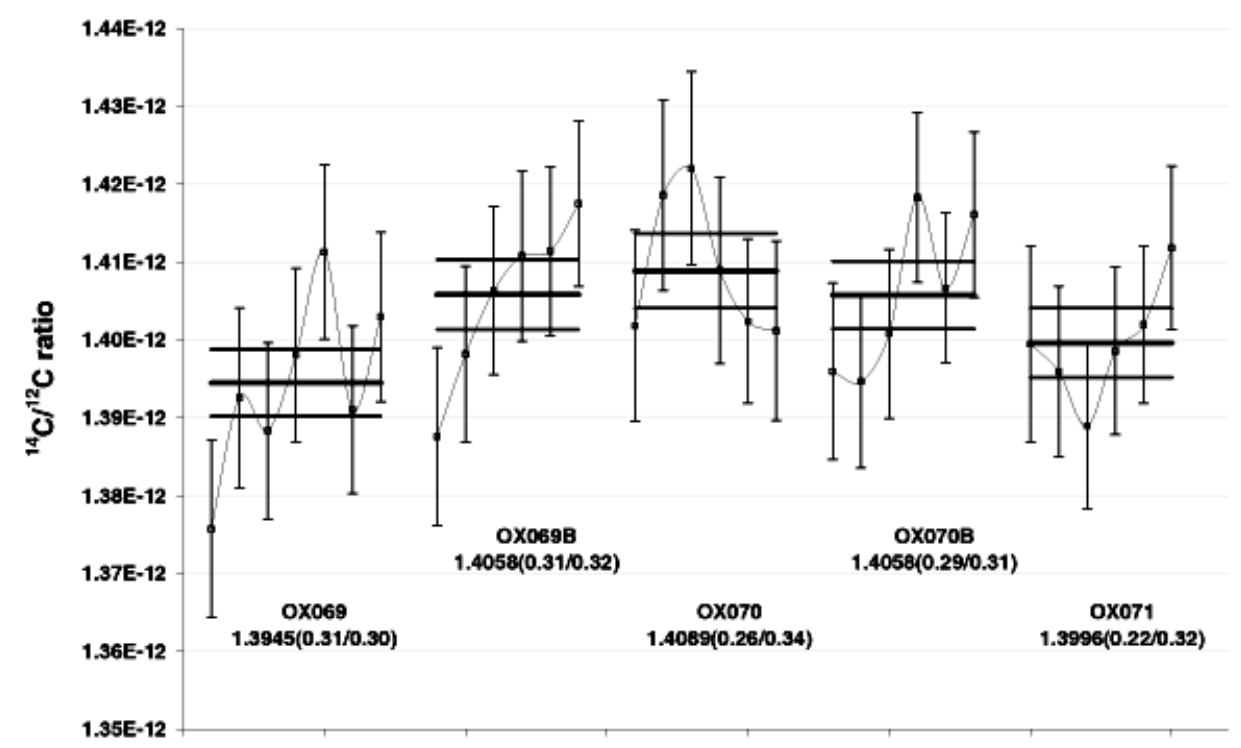

Figure $1{ }^{14} \mathrm{C} /{ }^{12} \mathrm{C}$ ratio measured in different HOxII cathodes. The average of the runs for each individual cathode is shown, and (internal/external) errors are presented. B indicates a replicate cathode from the same material.

runs for individual cathodes are shown (\%o). All values show very good agreement, but it is clear that replicate cathodes show an even better agreement, although in some cases the replicate samples presented quite different currents. We may conclude that the current correction is important, and that the small differences in values come mainly from sample preparation. The mean value of the averages, $1.03465(0.31)$, is in good agreement with the mean value of all the runs, $1.03486(0.12)$.

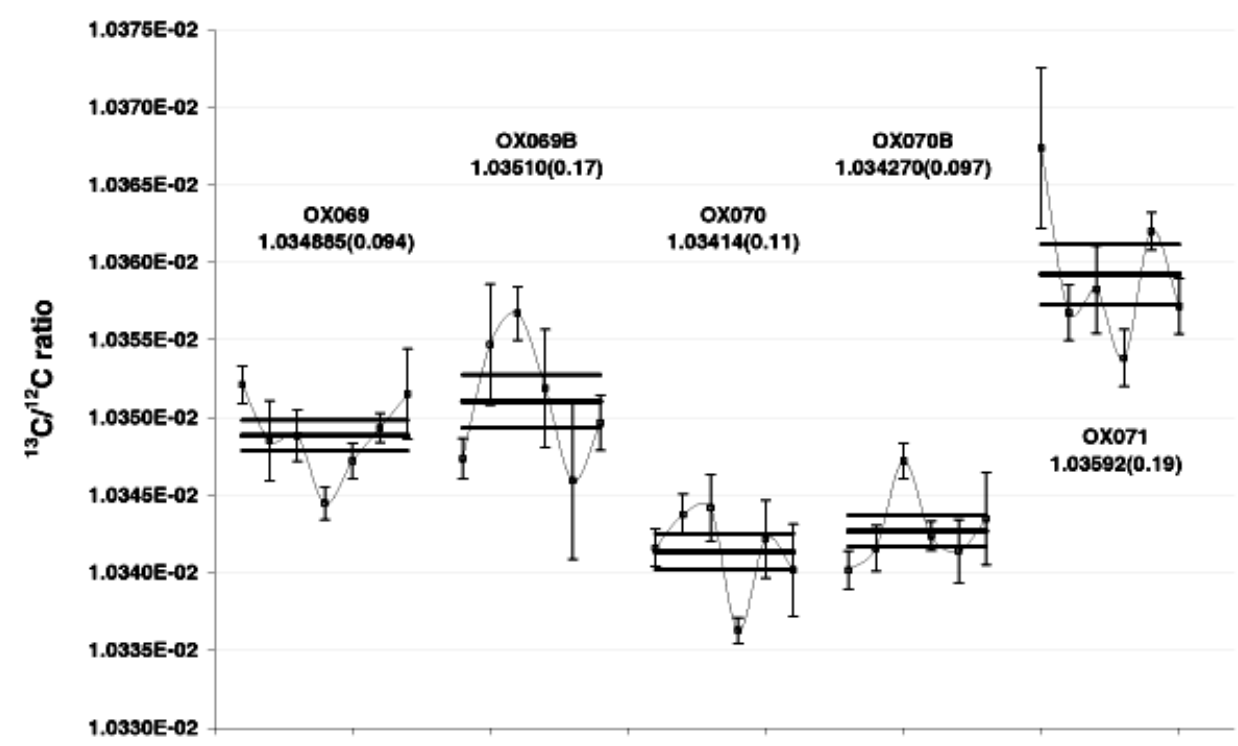

Figure $2{ }^{13} \mathrm{C} /{ }^{12} \mathrm{C}$ ratio measured and current corrected in different HOxII cathodes. The average of the runs for each individual cathode is shown and (external) errors are presented. B indicates a replicate cathode from the same material. 
For blank samples, we use different materials. Unprocessed graphite from Alfa Aesar (graphite powder 200 mesh, 99.9995\% metal basis) is measured routinely, obtaining $\mathrm{F}_{\mathrm{m}}$ values of $\sim 0.25$ (defined as the normalized sample ratio/normalized standard ratio expressed as a percentage, Donahue et al. 1990). As chemistry blanks, we use anthracite, charcoal, and C1 reference material. Background values for these processed samples lie around $F_{m}=0.65$. Table 1 shows the long-term variation of the charcoal material over more than $1 \mathrm{yr}$.

Table 1 Long-term evolution of charcoal material processed as a chemical blank and intercomparison sample FIRI E. Average values are $F_{m}=0.63 \pm 0.04$ and $\delta^{13} \mathrm{C}=-23.93 \pm 0.62$ for charcoal and age $\mathrm{BP}=11,830 \pm 70$ and $\delta^{13} \mathrm{C}=-27.73 \pm 0.88$ for FIRI E.

\begin{tabular}{lll|llc}
\hline \multicolumn{3}{c|}{ Charcoal } & \multicolumn{3}{c}{ FIRI E } \\
\hline Date & $\mathrm{F}_{\mathrm{m}}$ & $\delta^{13} \mathrm{C}$ & Date & Age BP & $\delta^{13} \mathrm{C}$ \\
\hline $18 / 07 / 07$ & $0.62 \pm 0.03$ & $-23.47 \pm 0.26$ & $15 / 02 / 07$ & $11,860 \pm 100$ & $-28.1 \pm 1.1$ \\
$07 / 11 / 07$ & $0.78 \pm 0.03$ & $-23.87 \pm 0.57$ & $29 / 05 / 07$ & $11,640 \pm 80$ & $-25.2 \pm 1.0$ \\
$08 / 01 / 08$ & $0.64 \pm 0.04$ & $-23.29 \pm 0.47$ & $18 / 07 / 07$ & $11,930 \pm 50$ & $-28.15 \pm 0.57$ \\
$11 / 02 / 08$ & $0.49 \pm 0.05$ & $-23.53 \pm 0.53$ & $17 / 10 / 07$ & $11,890 \pm 50$ & $-29.58 \pm 0.82$ \\
$21 / 04 / 08$ & $0.48 \pm 0.02$ & $-22.25 \pm 0.29$ & $08 / 01 / 08$ & $11,820 \pm 60$ & $-27.63 \pm 0.77$ \\
$24 / 06 / 08$ & $0.60 \pm 0.05$ & $-23.56 \pm 0.41$ & & & \\
$28 / 07 / 08$ & $0.67 \pm 0.04$ & $-27.04 \pm 0.31$ & & & \\
$06 / 11 / 08$ & $0.80 \pm 0.02$ & $-24.4 \pm 1.4$ & & & \\
\hline
\end{tabular}

In routine measurement, for each target several runs of $\sim 300 \mathrm{~s}$ are performed divided into 10 cycles of $30 \mathrm{~s}$ each in order to be able to eliminate any of these cycles in case there is a temporary problem. The current weighted average value is calculated from the runs to obtain the final ratio of the target. Data evaluation follows the steps shown in Rom et al. (1998). In the case of HOxII samples, the average from the different targets is calculated for both ${ }^{14} \mathrm{C} /{ }^{12} \mathrm{C}$ and ${ }^{13} \mathrm{C} /{ }^{12} \mathrm{C}$ ratios. The ${ }^{13} \mathrm{C} /{ }^{12} \mathrm{C}$ ratio is used to normalize samples to $\delta^{13} \mathrm{C}=-25 \%$, and background ratios are subtracted from both samples and standard. Finally, normalized ratios are corrected to the real value of HOxII.

${ }^{14} \mathrm{C}$ is measured by selecting charge state $2+$ after the stripper at a terminal voltage of $1 \mathrm{MV}$. Although ${ }^{7} \mathrm{Li}^{+}$could be an intense interference, a good use of the slits and apertures in the system allows reducing to a minimum of the count rate of ${ }^{7} \mathrm{Li}^{+}$in the detector, which has enough resolution to distinguish between the signals generated by ${ }^{14} \mathrm{C}^{2+}$ and 2 simultaneous ${ }^{7} \mathrm{Li}^{+}$ions. At this stage, our main concern is to reduce the presence of $\mathrm{CH}_{n}$ molecules, which we think is the main cause of the background.

\section{FIRST RESULTS}

Since May 2007, the facility has been working as a service for the scientific community and interested public. Most samples are dedicated to dating, but we have also performed other applications. Also, as a continuous internal test, several reference and intercomparison samples are measured during the batches to check results (Rozanski et al. 1992; Scott 2003). Results for these samples can be seen in Table 2. For each sample, the average calculated from a variable number of different targets individually prepared and measured is shown. The corresponding error is the maximum between SDOM and error calculated from a quadratic propagation. Final errors for a single target range from about 4-9\%o for samples not too close to background. In these kinds of near-background samples, the final error is usually between $3-9 \%$ for a single target. From the results shown in Table 2 , it can be seen that there is a general good agreement between experimental and consensus values. Also, in the second set of samples of the VIRI exercise, the agreement is very good (Scott et al. 2007, 2008). 
Table 2 Results for IAEA, FIRI, and VIRI samples. Age $\mathrm{BP} / \mathrm{F}_{\mathrm{m}}$ and $\delta^{13} \mathrm{C}$ average values and the corresponding error calculated from different targets are shown.

\begin{tabular}{lcc|cc}
\hline & \multicolumn{2}{c|}{ Age BP/F $F_{\mathrm{m}}$} & \multicolumn{2}{c}{$\delta^{13} \mathrm{C}$} \\
\cline { 2 - 5 } & Experimental & Consensus & Experimental & \multicolumn{1}{l}{ Consensus } \\
\hline C1 & $0.62 \pm 0.05$ & $0.02 \pm 0.02$ & $0.89 \pm 0.94$ & $2.42 \pm 0.11$ \\
C3 & $129.48 \pm 0.57$ & $129.41 \pm 0.06$ & $-28.0 \pm 2.5$ & $-24.98 \pm 0.49$ \\
C4 & $0.35 \pm 0.11$ & $0.32 \pm 0.12$ & $-25.9 \pm 1.4$ & $-23.96 \pm 0.62$ \\
FIRI-E & $11,827 \pm 50$ & $11,822 \pm 23$ & $-27.73 \pm 0.72$ & $-29.3 \pm 0.6$ \\
FIRI-H & $2248 \pm 30$ & $2229 \pm 8$ & $-25.86 \pm 0.80$ & $-25.2 \pm 1.4$ \\
FIRI-I & $4548 \pm 52$ & $4499 \pm 13$ & $-25.1 \pm 1.1$ & $-23.8 \pm 0.8$ \\
VIRI-A & $107.51 \pm 0.38$ & $109.1 \pm 0.665$ & $-26.82 \pm 0.41$ & - \\
VIRI-B & $2887 \pm 55$ & $2809.0 \pm 57.4$ & $-22.9 \pm 2.8$ & - \\
VIRI-C & $108.79 \pm 0.44$ & $110.7 \pm 0.537$ & $-26.71 \pm 0.59$ & - \\
VIRI-D & $2,880 \pm 33$ & $2838.0 \pm 59.2$ & $-21.94 \pm 0.36$ & - \\
VIRI-E & $37,200 \pm 1400$ & - & $-24.1 \pm 1.2$ & - \\
VIRI-F & $2500 \pm 25$ & - & $-22.70 \pm 0.44$ & - \\
VIRI-G & $952 \pm 48$ & - & $-22.19 \pm 0.75$ & - \\
VIRI-H & $9563 \pm 35$ & - & $-18.7 \pm 2.6$ & - \\
VIRI-I & $8229 \pm 39$ & - & $-19.8 \pm 2.0$ & - \\
\hline
\end{tabular}

The first set of unknown samples measured at CNA consisted of 6 samples (CNA002 paper sample; CNA003-CNA007 parchment samples) from 5 different medieval manuscripts belonging to the University of Seville. The books had been previously dated by paleography. The results show a general good agreement between the paleographic and ${ }^{14} \mathrm{C}$ dates (see Figure 3), although 2 of the samples present a clear shift. One possibility is that the parchments were not used for a long time. Another possibility is that parchment was reused, which was a common practice in the Middle Ages. None of these possibilities is mentioned in the bibliography (Núñez-Gaitán 1997) nor can be easily proved. More samples are being currently analyzed for further study (Santos et al., in preparation).

Probability Distributions

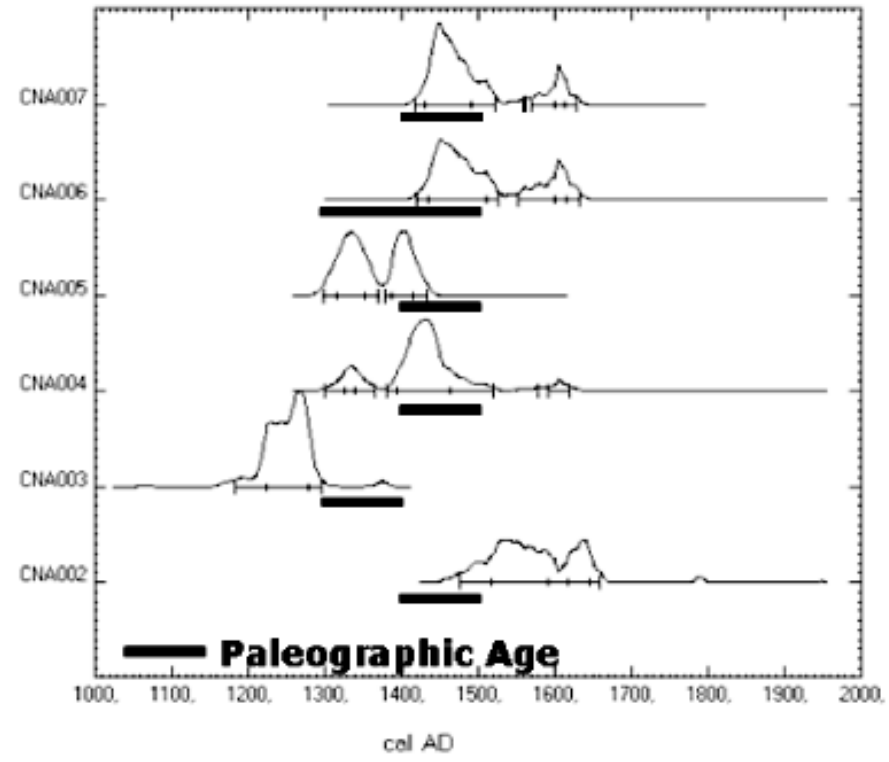

Figure 3 Probability distributions for medieval manuscripts. Samples CNA004 and CNA005 come from different parts of the same manuscript. Calibration is by CALIB (Stuiver and Reimer 1993; Stuiver et al. 2005). 
${ }^{14} \mathrm{C}$ measurements can also be applied to a variety of problems not related to dating. At CNA, we have performed a first set of determinations of ${ }^{14} \mathrm{C}$ in biodiesel samples. The aim of these determinations is to be able to distinguish between biodiesel samples containing different amounts of vegetable oil (Dijs et al. 2006). Samples were provided by a petrol company, and the amount of vegetable oil can only be assumed as approximate, ranging from about $2 \%$ to $100 \%$. Sample preparation followed the protocol described by ASTM (Standard D6866-06a, http://www.astm.org) with minor modifications. Results fit reasonably well with the expected values. These first results are promising and show that such a procedure could be used as a test to control biodiesel production procedures.

\section{SUMMARY}

Performance and the first results of the new ${ }^{14} \mathrm{C}$ laboratory at CNA (Seville, Spain) are presented. The short- and long-term stability is presented by the results on HOxII standards, blanks, and intercomparison samples. Results for certificated and intercomparison samples are in good agreement with certified or consensus values. Also, the first results on unknown samples for dating are presented, together with environmental applications.

\section{ACKNOWLEDGMENTS}

This work has been partially financed by the project EXC/2005/RNM-419 of the Junta de Andalucía. The authors would like to thank all the staff at the ETH AMS group for all their help during the last few years. Special thanks are given to Martin Suter, Hans-Arno Synal, Georges Bonani, and Irka Hajdas for their help with AMS and ${ }^{14} \mathrm{C}$. Also, thanks go to the rest of the members of the AMS group of the CNA, and to HVEE for their continuous technical support.

\section{REFERENCES}

Arslanov KA, Svezhentsev YS. 1993. An improved method for radiocarbon dating fossil bones. Radiocarbon 35(3):387-91.

Chamizo E, López-Gutiérrez JM, Ruiz-Gómez A, Santos FJ, García-León M, Maden C, Alfimov V. 2008. Status of the compact $1 \mathrm{MV}$ AMS facility at the Centro Nacional de Aceleradores (Spain). Nuclear Instruments and Methods in Physics Research B 266(10): 2217-20.

Dijs IJ, Windt E, Kaihola L, Borg K. 2006. Quantitative determination by ${ }^{14} \mathrm{C}$ analysis of the biological components in fuels. Radiocarbon 48(3):315-23.

Donahue DJ, Linick TW, Jull AJT. 1990. Isotope-ratio and background corrections for accelerator mass spectrometry radiocarbon measurements. Radiocarbon 32(2):135-42.

Hajdas I, Bonani G, Thüt J, Leone G, Pfenninger R, Maden C. 2004. A report on sample preparation at the ETH/PSI AMS facility in Zurich. Nuclear Instruments and Methods in Physics Research B 223-224:267-71.

Klein MG, Mous DJW, Gottdang A. 2006. A compact 1MV multi-element AMS system. Nuclear Instruments and Methods in Physics Research B 249(1-2):764-7.

Klein MG, van Staveren HJ, Mous DJW, Gottdang A. 2007. Performance of the compact HVE 1 MV multielement AMS system. Nuclear Instruments and Methods in Physics Research B 259(1):184-7.
Longin R. 1971. New method of collagen extraction for radiocarbon dating. Nature 230(5291):241-2.

Núñez-Gaitán A. 1997. Manoscritti anteriori al XVI secolo nella Biblioteca Generale Universitaria di Siviglia. A F.A. 091:017/BUS, General Library of the University of Seville.

Olsson I. 1986. Radiocarbon dating. In: Berglund BE, editor. Handbook of Holocene Palaeoecology and Palaeohydrography. Chichester: John Wiley \& Sons. 273 p.

Piotrowska N, Goslar T. 2002. Preparation of bone samples in the Gliwice radiocarbon laboratory for AMS radiocarbon dating. Isotopes in Environmental and Health Studies 38(4):267-75.

Rom W, Golser R, Kutschera W, Priller A, Steier P, Wild E. 1998. Systematic investigations of ${ }^{14} \mathrm{C}$ measurement at the Vienna Environmental Research Center. Radiocarbon 40(1):255-63.

Rozanski K, Stichler W, Gonfiantini R, Scott EM, Beukens RP, Kromer B, van der Plicht J. 1992. The IAEA ${ }^{14} \mathrm{C}$ intercomparison exercise 1990. Radiocarbon 34(3):506-19.

Santos FJ, Gómez Martínez I, García León M. In preparation. Dating of medieval manuscripts from the University of Seville. Presented at the 11th International Conference on Accelerator Mass Spectrometry, Rome, Italy, 2008. 
Scott EM. 2003. The Third International Radiocarbon Intercomparison (TIRI) and the Fourth International Radiocarbon Intercomparison (FIRI). Radiocarbon 45(2):135-408.

Scott EM, Cook GT, Naysmith P, Bryant C, O'Donnell D 2007. A report on Phase 1 of the 5 th International Radiocarbon Intercomparison. Radiocarbon 49(2):40926.

Scott EM, Cook GT, Naysmith P. 2008. Radiocarbon in- tercomparisons and the AMS community. Presented at the 11th International Conference on Accelerator Mass Spectrometry, Rome, Italy, 2008.

Stuiver M, Reimer PJ. 1993. Extended ${ }^{14} \mathrm{C}$ data base and revised CALIB $3.0{ }^{14} \mathrm{C}$ calibration program. Radiocarbon 35(1):215-30.

Stuiver M, Reimer PJ, Reimer RW. 2005. CALIB 5.0 [WWW program and documentation]. www.calib.org. 